\title{
Schelling e a Questão dos Postulados Práticos em "Cartas Filosóficas sobre o Dogmatismo e Criticismo"
}

[Schelling and the Question on the Practical Postulates in "Philosophical Letters on Dogmatism and Criticism]

\section{Marília Cota Pacheco*}

Resumo: Em "Cartas Filosóficas Sobre o Dogmatismo e o Criticismo" Schelling demonstra que tanto o dogmatismo quanto o criticismo têm um ponto comum: a incapacidade de demonstrar a dedução do processo de individuação de onde o múltiplo surge a partir de uma unidade absoluta. De um lado, Schelling ressalta que Espinosa podia de certo formular a questão "como o Absoluto sai de si mesmo", entretanto, lhe era inconcebível como o Absoluto pode sair de si mesmo. Por outro lado, Schelling considera que o criticismo pode provar a necessidade de proposições sintéticas para o dominio da experiência. "Mas ... por que há, em geral, um domínio da experiência?" A solução para as duas questões supracitadas se torna necessariamente um postulado prático. Pelo viés dos postulados práticos apresentaremos uma das raízes, por assim dizer, da dialética da imaginação no interior do pensamento de Schelling, a saber, a noção kantiana de incondicionado.

Palavras-chave: postulados práticos, criticismo, dogmatismo, incondicionado.

\begin{abstract}
According to the text "Philosophical Letters on Dogmatism and Criticism" Schelling demonstrates that both dogmatism and criticism have one common point: the inability to demonstrate the deduction of the individuation process from which the multiple arises from an absolute unity. On the one hand, Schelling points out that Spinoza could indeed formulate the question "how the Absolute comes out of himself", however, it was inconceivable to him how the Absolute can come out of itself. On the other hand, Schelling considers that criticism can prove the need for synthetic propositions for the domain of experience. "But ... why is there, in general, a domain of experience?" The two aforementioned issue's solution becomes necessarily a practical postulate. This paper aims to present one of the roots, so to speak, of the dialectic of imagination within Schelling's thought, namely: Kant's notion of unconditioned.
\end{abstract}

Keywords: practical postulates, criticism, dogmatism, unconditioned.

\footnotetext{
${ }^{*}$ Professora substituta no Departamento de Filosofia da Universidade de Brasília (UnB). Doutora em Filosofia pela USP. E-mail: mariliacota@gmail.com.
} 


\section{I - Introdução}

O texto "Cartas Filosóficas Sobre o Dogmatismo e o Criticismo" foi publicado entre 1795 e 1796 no Philosophisches Journal einer Gesellschaft Teutscher Gelehrten de Jena. Friedrich Wilhelm Joseph Schelling tinha 21 anos. Neste texto, Schelling demonstra que tanto o dogmatismo quanto o criticismo têm um problema comum: a incapacidade de demonstrar a dedução do processo de individuação de onde o múltiplo surge a partir de uma unidade absoluta. De um lado, Schelling ressalta que Espinosa podia de certo formular a questão "como o Absoluto sai de si mesmo", entretanto, lhe era inconcebível como o Absoluto pode sair de si mesmo. Por outro lado, Schelling considera que o criticismo pode provar a necessidade de proposições sintéticas para $o$ dominio da experiência. "Mas ... por que há, em geral, um domínio da experiência?" A solução para as duas questões supracitadas se torna necessariamente um postulado prático.

A originalidade de Schelling constitui no fato de que o autor especula a possibilidade de solucionar tal problema, considerando que a unidade absoluta da razão só pode aparecer, por assim dizer, pela necessidade de a razão em geral tornar-se prática. Contudo, é uma necessidade que não vale "para uma razão determinada, aprisionada nos grilhões de um sistema isolado; (...) a razão "deveria, onde o saber cessa, criar ela mesma um novo domínio, isto é, teria de tornar-se, de razão meramente cognoscente, uma razão criadora." 1

Antes de tratarmos do texto "Cartas Filosóficas Sobre o Dogmatismo e o Criticismo", apresentaremos uma das raízes, por assim dizer, da dialética da imaginação no interior do pensamento de Schelling, pelo viés da noção kantiana de incondicionado nos primeiros escritos de Schelling. Para tanto nos apoiaremos no ensaio de Eric Watkins "The early Schelling on the unconditioned" 2 onde a noção de incondicionado em Schelling é apresentada através de dois de seus primeiros escritos, a saber: Über die Möglichkeit einer Form der Philosophie überhaupt-1794 (Sobre a possibilidade de uma forma absoluta de filosofia) e Vom Ich als Prinzip der Philosophie oder über das Unbedingte im menschlichen Wissen - 1795 (Do eu como o princí-

\footnotetext{
${ }^{1}$ Schelling, F.W.J. “Cartas Filosóficas sobre o Dogmatismo e o Criticismo”, in: Textos escolhidos. São Paulo, Ed. Nova Cultural, 1989; tradução de Rubens Rodrigues Torres Filho, p.

${ }^{2}$ Watkins, Eric. "The early Schelling on the unconditioned", in: Interpreting Schelling: Critical Essays. Edited By Lara Ostaric, Cambridge University Press, 2014, pp. 10-31.
} 
pio da filosofia, ou Sobre o Incondicionado no Conhecimento $\mathrm{Hu}-$ mano).

\section{II - Eric Watkins: Kant e o incon- dicionado}

Em seu ensaio, Watkins ressalta o projeto global de Kant na Crítica da Razão Pura:

Os resultados a que Kant chega são: podemos ter cognição sintética a priori somente de objetos que nos são dados em sensibilidade (aparências) e que objetos que não nos são dados na sensibilidade (coisas em si) podem ser pensados mas não percebidos. Os objetos da metafísica tradicional, como Deus, a alma e nossa liberdade, não são, Kant pensa, objetos que podem ser dados a nós em sensibilidade, sua análise revela limites fundamentais sobre o que podemos conhecer, limites que destroem a possibilidade da metafísica tradicional. (...) Kant acrescenta que devemos ainda usar nossas ideias dos objetos da metafísica tradicional, mas apenas como princípios reguladores, de modo a organizar as aparências de maneiras sistemáticas, $(. ..){ }^{3}$

Dentre as muitas descrições da razão que Kant fornece, Watkins considera que a mais interessante e inovadora é que "a razão é uma faculdade ativa que busca a totalidade das condições para o que é condicionado e pode assim encontrar um lugar de descanso apropriado apenas identificando o incondicionado." 4 Kant introduz essa caracterização da razão mostrando como ela pode explicar os silogismos na lógica por meio do uso lógico da razão. A ideia básica é que um silogismo é uma relação racional entre duas premissas e uma conclusão onde as premissas de um silogismo contêm as condições de sua conclusão, as quais podem, portanto, ser condicionadas pelo que está contido em suas premissas. ${ }^{5}$

Segue-se que, tipos diferentes de silogismos dependem dos diferentes tipos de relações de condicionamento lógico (por exemplo, categórico, hipotético e disjuntivo). Além disso, uma vez que a razão tenha identificado as premissas a partir das quais uma

\footnotetext{
${ }^{3}$ Idem, pp. 13-14.

${ }^{4}$ Idem, p. 14.

${ }^{5}$ C.f. Watkins, op. cit. p. $14-15$.
} 
determinada cognição segue, ela continuará a procurar por outras premissas a partir das quais as premissas originais seguirão, por sua vez, como conclusões. O resultado claro é que a razão procura identificar uma série de silogismos interconectados, que vão desde cognições mais específicas, até as cognições mais gerais mais elevadas. Kant estende o escopo da razão para além dos silogismos, introduzindo o que ele chama de uso real da razão. Enquanto o uso lógico da razão diz respeito às diferentes relações de condicionamento entre os conceitos de silogismos, o uso real da razão diz respeito às relações de condicionamento que se estabelecem entre os objetos. ${ }^{6}$

Assim como com o uso lógico da razão, também no seu uso real, a razão busca pela completude das condições para os objetos condicionados e, portanto, para o incondicionado. Ao estender as relações condicionadoras reais ao incondicionado, a razão exige que os objetos sejam incondicionados em relação a (1) sua magnitude e, assim, constituem o mundo como uma totalidade; (2) sua composição, de tal modo que esse mundo consiste, em última análise, em uma série simples ou infinitamente divisível de partes; (3) sua causalidade, exigindo causas não causadas, ou liberdade absoluta, ou uma regressão infinita de causas; (4) sua atualidade, exigindo um ser necessário; (5) seu status como estados mentais (para representações), exigindo um sujeito absoluto, ou alma; e (5) sua possibilidade, requerendo um ens realissimum como base de sua possibilidade. $^{7}$

Ao tentar explicar os objetos condicionados que experimentamos, a razão está comprometida com a existência de algo incondicionado em cada um desses aspectos, porque, pelo menos para nossa razão, a existência de algo condicionado implica a existência de algo não condicionado. Ao mesmo tempo, Kant também tenta desmascarar as falácias que são supostamente cometidas em todos os argumentos dogmáticos que pretendem transmitir a cognição do mundo como uma totalidade, a alma e Deus. Na Crítica da Razão Pura, ${ }^{8}$ Kant faz uma distinção entre condições cognitivas, as exigências da razão, que podem ser lógicas, epistêmicas ou metafísicas. Por conseguinte, é perfeitamente apropriado sustentar que a

\footnotetext{
${ }^{6}$ Idem, p. 15.

${ }^{7}$ Ibidem.

${ }^{8}$ Ibidem.
} 
razão exige que postulemos a existência de objetos incondicionados, mesmo que não seja possível para nós conhecê-los. Isto é, mesmo que nos seja negada a plena cognição de tais objetos, ainda é possível ter um certo tipo de fé ou crença racional [Glaube] em tais objetos.

\section{Watkins ressalta:}

Epistemologicamente, a razão exige que procuremos um princípio incondicionado a partir do qual todas as outras cognições sejam derivadas (via silogismos). (...) Metafisicamente, a razão exige que usemos nossas ideias dos objetos tradicionais da metafísica como princípios reguladores, mas (...) também exige que postulemos a existência real de algo não condicionado que condiciona os diferentes objetos que experimentamos como condicionados em várias maneiras. Na prática, a razão exige crença na realidade dos objetos incondicionados de Deus, da liberdade e da imortalidade da alma. ${ }^{9}$

Com esse esboço da noção kan- tiana de incondicionado, passemos ao trabalho filosófico do jovem Schelling.

\section{III - o incondicionado no jovem Schelling}

No período entre 1794-1800 a questão fundamental é a relação de Schelling com Fichte. Entretanto, na medida em que há uma diferença essencial quanto à origem filosófica de ambos, seria errado caracterizar Schelling como um simples discípulo de Fichte. Segundo Schulz, Fichte foi completamente determinado pela filosofia de Kant. Fichte já vê na apercepção transcendental (o eu penso que necessariamente deve acompanhar todas as minhas representações) a possibilidade de colocar o Eu como princípio essencial da filosofia, na medida em que o sujeito também se torna objeto através do esquematismo da imaginação. Enquanto fundamento da possibilidade do saber da consciência finita, esse Eu deve ser pressuposto, contudo sempre permanece velado.

O jovem Schelling, por sua vez, não parte de uma tal crítica sobre a possibilidade do saber. Ele se esforça para alcançar uma unidade última onde a totalidade esteja em concordância. Esse inte-

${ }^{9}$ Watkins, op. cit. p. 15-16. 
resse por uma unidade originária foi proporcionado essencialmente pela filosofia de Espinosa, através do texto de Jacobi Über die Lehre des Spinoza in Briefen an Moses Mendelssohn. Schelling parece ter encontrado em Espinosa o autor que se decide por um incondicionado conhecido (bekannte) que não existe por si enquanto pessoa colocada acima do mundo. A expressão formal dessa unidade é hen kai pan. Nos primeiros escritos de Schelling encontramos várias vezes tal expressão formal da unidade, que ele procura integrar à filosofia de Fichte.

Segue-se que as reflexões de Fichte sobre o Eu como princípio conduzem Schelling ao seguinte discernimento: o incondicionado não pode ser buscado no âmbito da essência material disponível (dinglich-vorhandenen) na medida em que, necessariamente, uma coisa surge a partir do Eu, ou seja, ao conhecer todos os objetos, o Eu torna os objetos cognoscíveis. Em concordância com Fichte, Schelling esclarece que o incondicionado nunca pode encontrar-se naquilo que pode ser determinado ou conhecido; o incondicionado só pode se situar naquilo que é determinante (bedingend). Enquanto tal, o incondicionado só pode ser o Eu absoluto enquanto princípio de todo saber. Essa passagem de Espinosa a Fichte carrega consigo um sério problema. Para Schelling, o Eu absoluto enquanto princípio incondicionado não se manifesta como princípios fundamentais reflexivos que se tornam conhecidos da consciência finita. Ele entenderá o Eu absoluto como um último princípio ainda acima de toda separação que se encontra fora da unidade originária.

Nesse sentido, permanece espinosista, mas, por outro lado, numa carta a $\mathrm{Hegel}^{10}$, esclarece o que o diferencia de Espinosa: o incondicionado só pode ser o Eu como liberdade absoluta. Ao colocar o Eu absoluto em oposição à esfera da determinação finita, Schelling se defronta obrigatoriamente com duas questões: 1) como o incondicionado em si mesmo pode ser alcançado por nós? 2) como, a partir desse incondicionado enquanto puro ser, podemos conhecer o mundo determinado pela diversidade? Os textos de Schelling entre 1794 e 1800 mostram as diversas tentativas do autor para solucionar o problema em questão e, por conseguinte, mostram também as diferentes maneiras como foi formulado.

No texto Vom Ich... Schelling modela o princípio de todo saber

\footnotetext{
${ }^{10}$ C.f. in: System des transzendentalen Idealismus, Hamburg, Meiner, 2000; “Einleitung”, p. XII.
} 
de modo genuinamente idealista. A argumentação é: todo saber é saber de algo, caso contrário não haveria nenhum saber real; entretanto, deve haver no saber um fundamento originário de toda a realidade. Esse fundamento originário só pode ser incondicionado, ou aquilo que só é concebível através do seu ser, isto é, o fundamento originário só pode ser aquilo pelo que o ser e o pensar coincidem. Esse pelo que é a absolutez do eu sou, de tal modo que o meu eu contém um ser que antecede todo pensar e todo representar; esse ser é antes e depois de ser pensado simplesmente porque ele é enquanto pensa a si mesmo, ou ainda: ele é porque ele apenas pensa a si mesmo e ele pensa a si mesmo porque ele é ${ }^{11} \mathrm{e}$, justamente por isso, a forma originária do Eu absoluto está de acordo com a sua pura identidade e sua absoluta liberdade. Schelling demonstra a determinação do Eu absoluto em suas formas subordinadas de acordo com as categorias kantianas: o Eu absoluto da quantidade é segundo a unidade absoluta, o da qualidade segundo a realidade absoluta, o da relação segundo a substancialidade e causalidade absoluta e o da modalidade segundo o puro e absoluto ser ${ }^{12}$.

Como bem ressalta Watkins, o prefácio do texto "Do eu como o princípio (...)" deixa margem para acreditarmos que os primeiros esboços do pensamento de Schelling dizem respeito ao início de seus estudos sobre Kant, sobretudo a noção kantiana de incondicionado. Por quê? Ora, se se aceita o argumento de Kant de que, através das relações condicionantes, o conceito de condicionado leva ao de incondicionado, então o que Schelling explicitamente afirma no "Do eu como o princípio (...)" é que "o único critério que alguém pode usar para estabelecer o primeiro princípio da filosofia é aquele de ser absolutamente incondicionado."13 Kant não explicita nenhum primeiro princípio de sua filosofia, contudo, Schelling como que toma os conceitos de condicionado e incondicionado que Kant enfatizou e estende o uso deles no contexto dos princípios, ainda no espírito de Kant.

Ao que tudo indica, em contrapartida à dedução reflexiva de Fichte, Schelling apresenta uma descrição ontológica do Eu absoluto sob o prisma das determinações finitas para integrá-las à ab-

\footnotetext{
${ }^{11}$ In: Vom Ich als Princip der Philosophie oder über das Unbedingte im menschlichen Wissen (1795); Surkamp Verlag, Band I, p. I/1, 167.

${ }^{12}$ Idem, 160.

${ }^{13}$ Watkins, op. cit. pp. 18-19.
} 
solutez do Eu e elevá-las acima da esfera finita. Então, como a integração é mantida se o Eu absoluto está acima de seu próprio eu consciente? Schelling esclarece que a autoconsciência pressupõe o risco de se perder o $\mathrm{Eu}^{14}$, pois o eu que aparece na consciência não é mais o Eu absoluto puro, para o qual, de um modo geral, não há nenhum objeto e que tampouco pode vir a ser objeto. O Eu absoluto em si mesmo não pode vir à consciência de modo mediato, ele só pode ser incluído na consciência de modo imediato. A única inclusão imediata é a intuição. Mas a intuição do Absoluto não pode ser de modo algum uma intuição sensível, ela só pode ser intelectual, pois a intuição sensível só é produzida a partir de seu objeto concreto, enquanto a intuição intelectual encerra em si mesma uma unidade imediata de um intuinte e de um intuído: "Onde há objeto, há intuição sensível e vice-versa. Logo, onde não há nenhum objeto, isto é, no Eu absoluto, não há nenhuma intuição sensível, portanto, ou não há absolutamente intuição intelectual, ou há absolutamente intuição intelectual. O Eu absoluto é, para si mesmo, determinado como puro Eu na intuição intelectual". ${ }^{15}$ Aqui, a intuição intelectual, entendida como uma espécie de entrega do eu consciente ao puro Eu onde não há oposição, assegura e mantém a integração das determinações finitas no Eu absoluto que está acima de seu eu consciente.

Contudo, ainda permanece a questão: como é possível, a partir do infinito, pormos o Absoluto como uma unidade indistinta em contraposição à esfera finita sem perdermos a relação de pura identidade do Eu absoluto e, ao mesmo tempo, produzirmos juízos sintéticos? Ela é, em suma, a questão sobre a síntese da unidade infinita e da diversidade finita e é justamente a questão principal do texto de 1795 "Cartas Filosóficas sobre o Dogmatismo e o Criticismo" (Philosophischen Briefen über Dogmatismus und Kriticismus).

Nesse texto, na medida em que o Absoluto está posto como identidade acima de toda oposição e, de um modo geral, uma síntese só pode surgir através da oposição, o nosso próprio questionamento sobre a síntese do infinito e do finito constitui a condição de tal

\footnotetext{
${ }^{14}$ Vom Ich Idem, 180 .

15 "Wo Objekt ist, da ist sinnliche Anschauung, und umgekehrt. Wo also kein Objekt ist, d.h. im absoluten Ich, da ist keine sinnliche Anschauung, also entweder gar keine oder intellektuale Anschauung. Das Ich also ist für sich selbst als blosses Ich in intellektualer Anschauung bestimmt." In: Vom Ich als Princip der Philosophie oder über das Unbedingte im menschlichen Wissen (1795); Surkamp Verlag, Band I, p. I/1, 181. Tradução nossa.
} 
síntese. Assim, a condição da síntese está dada, porém, o problema não pode ser totalmente resolvido no âmbito teórico, pois a intuição intelectual, na sua unificação imediata, joga fora, por assim dizer, toda oposição. Nessa imediatez da intuição intelectual, a oposição está numa espécie de estado de morte (Zustand des Todes).

A reflexão sobre esse estado da oposição se apresenta necessariamente como um regresso em que nos encontramos privados de nós mesmos e, portanto, não fornece nenhuma resposta. Segue-se que, justamente porque nessa reflexão a oposição do intuinte e do intuído está suspensa, essa reflexão será explicada ou de maneira espinosista (suspensão de toda egoidade num objeto absoluto), ou de maneira idealista (suspensão de toda objetividade num Eu absoluto).

Quando Schelling demonstra que essas duas interpretações são as únicas corretas, ele também está provando que a reflexão, da qual ambas partem, deve ser determinada como Eu absoluto. Consequentemente, no âmbito teórico dessas duas interpretações, a resposta para a questão sobre a passagem do infinito ao finito será sensatamente a mesma: do infinito ao finito não há passagem. A solução desse problema só pode ser apresentada no âmbito prático a partir da nossa ten- dência natural rumo ao infinito, isto é, pelo nosso próprio empenho para realizar o Absoluto em nós mesmos através da atividade infinita, a ideal. Entretanto, justamente porque a intuição intelectual não proporciona nenhum conhecimento do Absoluto, este não terá mais lugar no homem finito que, a partir do estado imediato da intuição intelectual, precisa voltar para si mesmo na esfera finita e, através da reflexão, banir o esforço rumo ao infinito.

Apenas o uso imanente que fazemos do princípio absoluto, na filosofia prática, para o conhecimento de nossa destinação, nos redireciona para fora do Absoluto. Enfim, nas Cartas, para responder à questão sobre a síntese da unidade infinita e da diversidade finita, Schelling mostrou que essa questão só tem resposta no âmbito prático, através do uso imanente que fazemos da ideia do Absoluto.

\section{IV - A questão dos postulados em "Cartas Filosóficas sobre o Dogmatismo e o Criticismo"}

Na primeira Carta a questão dos postulados aparece através de uma censura ao kantismo adocicado dos teólogos que lecionavam em Tübingen, sobretudo Johann 
Flatt e Gottlieb Storr, ${ }^{16}$ isto é, Schelling refuta a chamada prova moral da existência de Deus. Basicamente seu argumento consiste no seguinte: na medida em que os teólogos de Tübingen entendem que a razão teórica é demasiado fraca para conceber um Deus, e a ideia de Deus só é realizável por exigências morais, eles entendem que a necessidade prática é mais premente que a teórica, desconsiderando que a razão teórica não encontra em parte nenhuma espaço para causalidade absoluta, admitem uma causalidade absoluta no âmbito da razão prática. Se assim o é, também precisam admitir que a razão teórica teria de ser ampliada pois uma "admissão prática”, segundo Schelling, é um assentimento teórico segundo a forma, mas que, segundo a matéria, segundo o fundamento, é prático. ${ }^{17}$ Com isso, Schelling reafirma a máxima da primeira Crítica: "do infinito ao finito não há passagem", isto é, podemos pensar o incondicionado, mas não podemos conhecê-lo.

Na segunda Carta, Schelling entende que a exigência de não se admitir nenhuma objetividade ab- soluta, é uma exigência própria de nosso ser originário e não apenas uma exigência da faculdade de conhecer. Noutras palavras: para Schelling, tomar a faculdade de conhecer como a própria razão é o grande equívoco dos teólogos de Tübingen:

Porque a primeira tentativa empreendida contra o dogmatismo só podia partir da faculdadede-conhecer, vós acreditastes poder imputar audaciosamente "a razão a culpa do malogro de vossa esperança. (...) Segundo vossa crença, o dogmatismo mesmo, que teria um fundamento mais profundo do que a simples faculdade-de-conhecer, zombaria de nossas provas. $^{18}$

$\mathrm{Na}$ terceira Carta, Schelling mostra que a Crítica da Razão Pura só alcança uma refutação negativa do dogmatismo, isto é, apresenta apenas a indemonstrabilidade teórica do dogmatismo, pois o criticismo só podia partir de um ponto que fosse comum a ele e ao dogmatismo. Por quê? Por-

\footnotetext{
${ }^{16}$ C.f. Torres Filho, Rubens Rodrigues in: nota de sua tradução de "Cartas Filosóficas sobre o Dogmatismo e o Criticismo", Textos escolhidos. São Paulo, Ed. Nova Cultural, 1989; tradução de Rubens Rodrigues Torres Filho, p. 5.

${ }^{17}$ Schelling, F.W.J. “Cartas Filosóficas sobre o Dogmatismo e o Criticismo”, in: Textos escolhidos. São Paulo, Ed. Nova Cultural, 1989; tradução de Rubens Rodrigues Torres Filho, p. 7.

${ }^{18}$ Idem, p. 9.
} 
que só há em geral sistemas diferentes se houver ao mesmo tempo um domínio comum a eles. Esse domínio comum é o que Schelling chama de "exílio do Absoluto; pois sobre o Absoluto seríamos todos unânimes, se nunca deixássemos sua esfera; e, se nunca saíssemos dela, não teríamos nenhum outro domínio para controvérsias." 19 O exílio do absoluto é a finitude, por isso o criticismo só poderia refutar o dogmatismo a partir da faculdade de conhecer, estabelecendo as condições de objetivação da experiência.

E ainda: para Schelling, a Crítica da Razão Pura só começou efetivamente sua luta a partir do problema que diz respeito ao ponto comum de toda filosofia e que Kant apresenta no início de sua obra com a pergunta: Como chegamos, em geral, a julgar sinteticamente Para Schelling, expressa de outro modo, a pergunta diz: Como chego, em geral, a sair do Absoluto e a ir a um oposto? Recorramos às palavras do autor para esclarecer a analogia estabelecida entre as duas questões.

Com efeito, uma síntese, em geral, surge pelo conflito da pluralidade com a unidade originária. Pois, sem conflito em geral, nenhuma síntese é necessária; onde não há pluralidade, há unidade pura e simples; mas se a pluralidade fosse o originário, mais uma vez não haveria síntese. (...) embora só possamos conceber a síntese por uma unidade originária contraposta à pluralidade, a Crítica da Razão Pura não podia (...) chegar àquela unidade $\mathrm{ab}$ soluta, porque, (...) só podia partir precisamente daquele fato de que parte a controvérsia da própria filosofia. ${ }^{20}$

O que Schelling parece explicitar aqui é que o sujeito, assim que julga objetivamente, sai de si mesmo e é obrigado a empreender uma síntese e, justamente por isso, o objeto não pode aparecer como absoluto em nenhuma síntese; se assim o fosse, o objeto como absoluto não deixaria subsistir nenhuma síntese. Até esse ponto o dogmatismo está teoricamente refutado. Contudo, Schelling ressalta $^{21}$ que a faculdade de conhecer está longe de ser esgotada com

\footnotetext{
${ }^{19}$ Idem, p. 10.

${ }^{20}$ Schelling, F.W.J. “Cartas Filosóficas sobre o Dogmatismo e o Criticismo”, in: Textos escolhidos. São Paulo, Ed. Nova Cultural, 1989; tradução de Rubens Rodrigues Torres Filho, p. 11.

${ }^{21}$ C.f. idem p. 12.
} 
a ação da síntese. Por quê? Porque na medida em que pressupõe que as ações meramente formais do sujeito não se submetem a nenhuma dúvida, uma crítica da faculdade-de-conhecer busca provar a marcha de toda síntese material pela marcha de toda síntese meramente formal, ou seja, pressupõe que o sujeito é obrigado a ir dos juízos condicionados aos incondicionados (por prosilogismos). Por conseguinte, tem de aceitar que a razão teórica visa necessariamente um incondicionado, "e justamente ao fazer isso, tem de aniquilar aquilo que acaba de edificar. Ou seja: enquanto permanece no domínio da síntese, ela triunfa sobre o dogmatismo; tão logo abandona esse domínio (...) a luta começa de novo."22

Schelling considera que a Crítica da Razão Pura demonstrou que a controvérsia sobre onde está o princípio daquela unidade que é expressa no juízo sintético não pode ser decidida na filosofia teórica e, ao fazê-lo a partir da faculdade-de-conhecer, a Crítica da Razão Pura permite, a partir da essência da razão, a dedução de dois sistemas diretamente opostos entre si, dogmatismo (realismo) e criticismo (idealismo).
Para Schelling, a "Crítica da $R a$ zão Pura ensinou ao dogmatismo como se tornar dogmatismo, isto é, um sistema de realismo objetivo fundado em si mesmo." 23 E se alguém julgar que tal "afirmação é inteiramente contrária ao espírito da Crítica" (...), Schelling contraargumenta:

Permita-me, portanto, recordar-lhe, também de antemão, apenas uma parte da Crítica, que justamente até agora, foi menos esclarecida de todas: refiro-me à parte que trata da coisas em si. Se se acredita que a Crítica da Razão Pura deve fundar apenas o criticismo, então, justamente nesse ponto, não há como salvá-la, ao que entendo, da acusação de inconsequência.

A noção de coisa em si da Crítica deixa subsistir o sistema do realismo ou dogmatismo consequente porque Schelling a entende como uma limitação que produz no Eu (enquanto princípio) a tendência para se tornar objeto de modo que nessa sua objetivação ele se compreenderá como sujeito. Esse querer compreender a si mesmo como sujeito sem-

\footnotetext{
${ }^{22}$ Ibidem.

${ }^{23}$ Schelling, F.W.J. “Cartas Filosóficas sobre o Dogmatismo e o Criticismo”, in: Textos escolhidos. São Paulo, Ed. Nova Cultural, 1989; tradução de Rubens Rodrigues Torres Filho, p. 15.
} 
pre impulsiona o Eu para a sua objetivação mais elevada. Entretanto, Schelling demonstra que nesse processo o Eu é parcial, pois nele o Eu consuma apenas o seu agir objetivo e, por conseguinte, ainda não reconhece a si mesmo como sujeito. Esse caminho para a autoconsciência só se torna conhecido em virtude do filósofo que realiza o Eu objetivo fundado na sua própria autoconsciência. ${ }^{24}$

Isso significa que, para Schelling, no particular da sensação do ser limitado, a atividade ideal determina o limite da atividade real como uma esfera de passividade. $\mathrm{O} \mathrm{Eu}$ se cinde em passividade e atividade apenas para não refletir a sua própria atividade limitante. Não ocorrendo essa reflexão, a passividade aparece necessariamente como uma efetividade estranha ao próprio Eu que a determina, isto é, a passividade aparece como uma efetividade da coisa em si que, de fato, é a sombra da atividade ideal que ultrapassou o limite, pois para o Eu intuir a si mesmo como o que sente ele precisa reintegrar ativamente em si o seu oposto, ou seja, reintegrar em si a passividade. ${ }^{25}$ E, para Schelling, esta é a possibilidade, em fi- losofia, de se deduzir dois sistemas diretamente opostos entre si. Por conseguinte, Schelling dirá na V Carta: "a Crítica da Razão Pura provou (...) que nenhum sistema - tenha ele o nome que tiver - é, em sua perfeição, objeto do saber, mas apenas objeto de uma ação, praticamente necessária, mas infinita." 26

Pode-se dizer que, para Schelling, o método dos postulados práticos foi estabelecido tanto para o dogmatismo quanto para o criticismo exprimirem o domínio do Absoluto. Na VI Carta, Schelling considera que Espinosa usou o método dos postulados pela mesma razão do criticismo, isto é: pela impossibilidade de conceber como saímos do absoluto para, pura e simplesmente opor algo a nós. Para Schelling, Espinosa afirma apenas uma causalidade imanente do objeto absoluto meramente porque lhe era inconcebível como o Absoluto pode sair de si mesmo, ou seja, ele podia de certo formular a questão, mas não soluciona-la, daí a função mais ampla do postulado na filosofia de Espinosa.

A ideia de Deus como causa imanente que existe com suas

\footnotetext{
${ }^{24}$ C.f. System des transzendentalen Idealismus, Hamburg, Meiner, 2000, pp. 55-57; Surkamp Verlag, Band I, p. I/3, 373-388.

${ }^{26}$ Schelling, F.W.J. “Cartas Filosóficas sobre o Dogmatismo e o Criticismo”, in: Textos escolhidos. São Paulo, Ed. Nova Cultural, 1989; tradução de Rubens Rodrigues Torres Filho, p.16.
} 
criaturas é atrativa para Schelling porque, assim como Espinosa, ele também parte do pensamento fundamental de que Deus, enquanto Absoluto, não pode ter nenhum objeto fora de si e, por conseguinte, não pode ser entendido, teoricamente, como um objeto, isto é, do lado de "fora". Resta que se, teoricamente, Deus não pode ser entendido como um objeto, então, Schelling tem que torna-Lo sujeito do discurso filosófico. Por quê? Vejamos: o axioma fundamental dos dois sistemas (dogmatismo e criticismo) é uma questão insolúvel teoricamente, a solução da questão sobre como chegamos a sair do Absoluto é uma solução que só pode se dar no campo da prática ou da subjetividade. Para o autor, a solução dessa questão se dá por um ato de escolha e, por isso, dizemos que se dá no campo da subjetividade; por conseguinte, dizemos que é por liberdade que encontramos a solução dessa questão.

Se, Schelling desreifica Deus, tornando-o sujeito do discurso filosófico, parece razoável considerar que a sua primeira definição para o Absoluto seja sujeito. Contudo, um sujeito que tem a necessidade interna de passar ao objeto, pois, na VI Carta, Schelling concebe uma espécie de faculdade produtiva realizadora, não pelo saber, mas pelo agir, mediante o qual, a razão criaria ela mesma, onde o saber cessa, um novo domínio, sem perder-se em vãs ficções e, assim, teria de tornar-se, de razão meramente cognoscente, uma razão criadora - de razão teórica, uma razão prática. "Mas a necessidade de se tornar prática vale para a razão em geral, não para uma razão determinada, aprisionada nos grilhões de um sistema isolado." 27

$O$ fato de Schelling considerar Deus o sujeito do discurso filosófico viabiliza uma outra noção de sua filosofia que, por sua vez, fundamenta a razão criadora, a saber: a identidade imediata, intrínseca de real e ideal. Essa identidade imediata é a essência do Absoluto e, justamente por isso, não pode ser conhecida mediante definições, mas apenas com a intuição não sensível.

Para finalizar: pelo viés da noção kantiana de incondicionado as "Cartas Filosóficas Sobre o Dogmatismo e o Criticismo" nos fornecem um bom indício do que leva Schelling a conceber posteriormente em Sistema do Idealismo Transcendental sua dialética da imaginação como forma sistemática do Eu enquanto princípio de uma consciência do mo- 
mento presente que surge, originariamente, de um passado transcendental. Nos textos de sua filosofia da identidade, ${ }^{28}$ essa forma sistemática será ampliada como uma forma formante de sujeito e objeto no Absoluto e, nisso, possibilita a fundamentação da essência da identidade alma - Absoluto na intuição intelectual, entendida como princípio e conhecimento que supera infinitamente toda determinação conceitual e, ao mesmo tempo, efetiva o princípio transcendental e a causa imanente da equipossibilidade volitiva e cognitiva do puro sujeitoobjeto. Noutras palavras: a filosofia alcança a reconstrução do Absoluto como sujeito-objeto de modo objetivo porque ela contempla algo que se revela numa ação de manifestação de si mesma como sujeito.

\section{Referências}

SCHELLING, Friedrich Wilhelm Joseph. Sämtliche Werke, ed. K. F. A. Schelling, Stuttgart, 1856/1861 (1 ${ }^{\circ}$ seção, vols. $1-10 ; 2^{\circ}$ seção, vols 1-4).

. Ausgewählte Schriften: in 6 Bd. / Frankfurt am Main: Suhrkamp - Verlag, - 1. Auflage 1985.

A Filosofia da Arte. Tradução de Márcio Suzuki. São Paulo, Edusp, 2001.

. Philosophische Briefe über Dogmatismus und Kriticismus (1795).

In: Friedrich Wilhelm Joseph Schelling, Historisch - Kritische Ausgabe, Reihe I: Werke; Werke 3, herausgegeben von Harmut Buchner, Wilhelm G. Jacobs und Annemarie Pieper. Stuttgart: Frommannn - Holzboog, 1982.

. System des transzendentalen Idealismus, Hamburg, Meiner, 2000. . Textos escolhidos. São Paulo, Ed. Nova Cultural, 1989; tradução de Rubens Rodrigues Torres Filho.

- Vom Ich als Princip der Philosophie oder über das Unbedingte im menschlichen Wissen (1795); Surkamp Verlag, Band I.

TORRES FILHO, Rubens Rodrigues. "O Simbólico em Schelling”, in: Ensaios de Filosofia Ilustrada, São Paulo, Editora Brasiliense, 1987.

\footnotetext{
${ }^{28}$ Tais como: A Filosofia da Arte. Tradução de Márcio Suzuki. São Paulo, Edusp, 2001. Filosofia e Religione (1804); A cura di Luigi Pareyson; traduzione di Valério Vera Milano, Mursia ed., 1987. Propedeutica della filosofia; traduzione di Fabio Palchetti, Pisa, ETS Editrice, 1991.
} 
WATKINS, Eric. "The early Schelling on the unconditioned", in: Interpreting Schelling: Critical Essays. Edited By Lara Ostaric, Cambridge University Press, 2014, pp. 10-31. 